
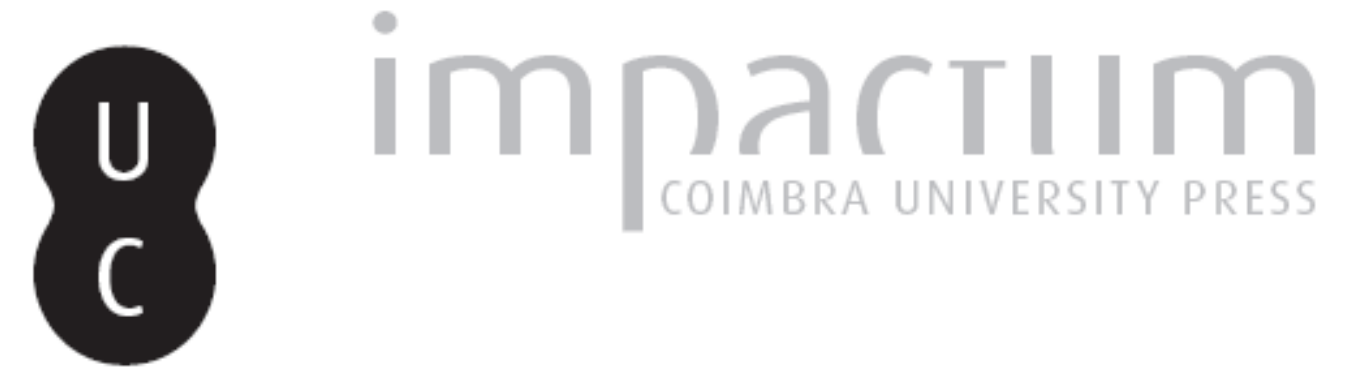

A vida pública de Sebastião José de Carvalho e Mello em Viena de Áustria (17441749)

Autor(es): $\quad$ Santos, Maria Alcina R. C. Afonso dos

Publicado por: Imprensa da Universidade de Coimbra

URL persistente:

URI:http://hdl.handle.net/10316.2/43858

DOI:

DOI:https://doi.org/10.14195/2183-8925_4-1_2

Accessed : $\quad$ 26-Apr-2023 08:00:18

A navegação consulta e descarregamento dos títulos inseridos nas Bibliotecas Digitais UC Digitalis, UC Pombalina e UC Impactum, pressupõem a aceitação plena e sem reservas dos Termos e Condições de Uso destas Bibliotecas Digitais, disponíveis em https://digitalis.uc.pt/pt-pt/termos.

Conforme exposto nos referidos Termos e Condições de Uso, o descarregamento de títulos de acesso restrito requer uma licença válida de autorização devendo o utilizador aceder ao(s) documento(s) a partir de um endereço de IP da instituição detentora da supramencionada licença.

Ao utilizador é apenas permitido o descarregamento para uso pessoal, pelo que o emprego do(s) título(s) descarregado(s) para outro fim, designadamente comercial, carece de autorização do respetivo autor ou editor da obra.

Na medida em que todas as obras da UC Digitalis se encontram protegidas pelo Código do Direito de Autor e Direitos Conexos e demais legislação aplicável, toda a cópia, parcial ou total, deste documento, nos casos em que é legalmente admitida, deverá conter ou fazer-se acompanhar por este aviso.

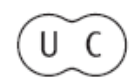




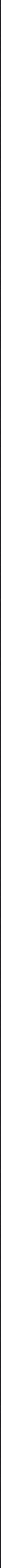


MARIA ALCINA R. C. AFONSO DOS SANTOS *

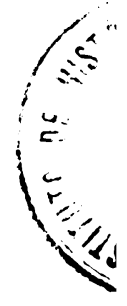

\section{A VIDA PÚBLICA \\ DE SEBASTIÃO JOSÉ DE CARVALHO E MELLO EM VIENA DE ÁUSTRIA}

(1744-1749)

A bibliografia sobre Sebastião José de Carvalho e Mello tem-se ocupado sobretudo na análise do período em que foi ministro de D. José I. As informações sobre a sua acção diplomática anterior são, de facto, muito escassas. No entanto, a maioria dos historiadores não deixa de referir, em termos encomiásticos ou depreciativos, a sua presença nas cortes de Londres e de Viena de Austria, como se houvesse já um perfeito conhecimento destas duas missões diplomáticas. Na realidade, continua, ainda, muito discutível a importância que elas tiveram na formação política e ideológica do Ministro de D. José I. Particularmente, a enviatura a Viena de Austria tem sido considerada ou de pouco interesse na definição das linhas de pensamento de Sebastião José de Carvalho e Mello (J. Lúcio de Azevedo), de significado muito relativo na história da diplomacia portuguesa (Eduardo Brazão), ou de decisiva influência nesse sentido, principalmente na assimilação das ideias do despotismo esclarecido e do iluminismo austríaccs (L. Cabral Moncada).

Consideremos, porém, através do estudo da correspondência do futuro Marquês de Pombal com ministros e diplomatas da corte portuguesa e de outras cortes estrangeiras, dois aspectos fundamentais da sua vida pública, possivelmente condicionantes da sua orientação política:

* Directora do Museu do Abade de Bagal. 


\section{Relações de Famúlia}

Em 25 de Janeiro de 1745 Sebastião José de Carvalho e Mello recebia, em Viena, uma carta de Frei Gaspar da Encarnação, referente ao assunto do seu casamento e à indispensável licença de $D$. João V. Afirmava estarem já informados dessa sua resolução o Rei, a Rainha e o Príncipe de Portugal ( ${ }^{1}$ ).

Com efeito, em 13 de Dezembro desse ano, Sebastião José de Carvalho e Mello casava com D. Leonor de Daun, pertencente a uma família de elevada nobreza do Império. Pelo esquema seguinte pode verificar-se a sua ascendência remontando à terceira geração $\left({ }^{2}\right)$ :

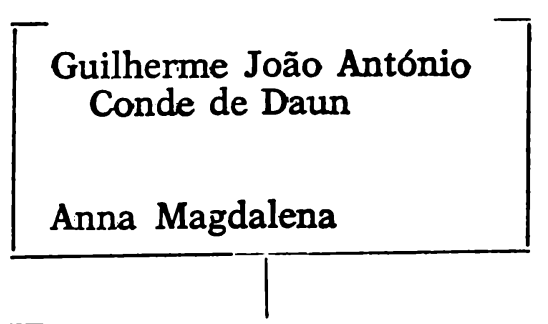

Henrique Ricardo Lourenço Conde de Daun
Francisco Paradis

Conde de Peyersperg

Maria Catarina Bárbara

Josefa Violanta

Condessa de Peyersperg

O pai de D. Leonor de Daun nascera em 14 de Abril de 1673 e era naquela data conselheiro de guerra e guarda-mor geral na Corte $\left({ }^{8}\right)$.

(') B. N. L., Col. Pomb., cod., 661, fl. 38, Carta de Frei Gaspar da Encarnação para Sebastião J. de Carvalho e Mello, Lisboa, 25 de Janeiro de 1745.

(2) B. N. L., Col. Pomb. cod., 640, fl. 38, Certidão de Baptismo da mãe de $\mathrm{D}$. Leonor de Daun, Viena, 9 de Junho de 1746.

(') Ibidem, fl. 30, Certidão de Baptismo de D. Leonor de Daun, Viena, 18 de Março de 1746. 
A mãe de D. Leonor de Daun nascera em 22 de Abril de 1691 e fora "dama de honor da Augustíssima Imperatriz Leonor Magdalena de saudosa memória...» ( $\left.{ }^{4}\right)$.

No casamento foram testemunhas da parte do marido, o príncipe Eugénio de Sabóia, e da parte da esposa, o príncipe de Liechtein, mordomo-mor da Corte $\left(^{5}\right)$.

D. Leonor de Duan nascera em 2 de Novembro de 1721, sendo padrinhos no seu baptismo D. Leonor, Condessa de Ulm, da casa de Peyersperg, e o Reverendo Ernesto Carlos, da mesma casa, cónego capitular e vigário geral de Passau ( $\left.{ }^{8}\right)$.

Do casamento de Sebastião José de Carvalho e Mello com D. Leonor de Daun foram testemunhas pessoas da maior representação na Corte de Viena. De uma parte, estiveram o Duque D. Manuel da Silva Tarouca «da Caz. e Regia Mag.d conselheiro Intimo actual, da Ordem Equestre do Tosão de Ouro e Presidente de Flandres» ( $\left.{ }^{7}\right)$, os Condes de Kimgsegy, de Weldefeld, de Kinsy, de Beruney, e, sem título indicado, os portugueses Gabriel da Cunha e Manuel Saldanha e Albuquerque.

Da outra parte, estiveram a mãe de D. Leonor, D. Violante Josefa condessa de Peyersperg, Henrique José Conde de Daun «de S. Cez. Mag.d Conselheiro Intimo, actualmente e mar rechal de campo" $\left({ }^{8}\right)$, o príncipe Carlos de Dietrichstein, os Condes Leopoldo de Windisgraf, J. F. de Seilern, de Colloredo, e Fernando de Harrach.

Este casamento de Sebastião José de Carvalho e Mello em Viena não desagradava em Lisboa. Frei Gaspar da Encarnação mandava-lhe os parabéns em carta já referida de 25 de Janeiro de 1745. No mesmo ano, escrevia-lhe Manuel Pereira de Sampaio, de Roma, nestes termos: "Sabendo que Vossa Senhoria, toma estado nessa corte e com acerto tão próprio do seu merecimento e das suas eleições, não posso dispensar-me deste acto, com o qual lhe dou os seguros daquele gosto

(4) Ibidem, fl. 37, Certidão do casamento dos pais de D. Leonor de Daun, Viena, 3 de Junho de 1746.

(António Joaquim Moreira, em Vida de Sebastião J. de Carvalho e Mello, manuscrito, B. N. L., F. G. diz que a mãe de D. Leonor de Daun era Joana Violante de Burgenberg. Este último nome não o encontramos em qualquer documento referente a D. Leonor de Daun ou à sua família).

( $\left.{ }^{5}\right)$ Ibidem, fls. 20 a 22 , Contrato de casamento de Sebastião J. de Carvalho e Mello, Viena, 3 de Junho de 1746.

(') Ibidem.

(') Ibidem, fl. 36. Certidão do casamento de Sebastião J. de Carvalho e Mello, 3 de Dezembro de 1746.

( $\left.{ }^{8}\right)$ Ibidem. 
com que sei dar-me os parabéns desta felicidade, não obstante para os tais efeitos faltar-me a fortuna de que Vossa Senhoria mo participasse...» $\left({ }^{8}\right)$. Evidentemente transparecia nestas palavras um ressentimento justificado.

O Cardeal da Mota manifestava-lhe em carta de 27 de Janeiro de 1746, o seu pleno agrado pela resolução de Sebastião José de Carvalho e Mello casar em Viena, com pessoa de tão nobre ascendência $\left({ }^{10}\right)$.

Marco António de Azevedo Coutinho e o P.' Carbone sempre concordaram com essa decisão, porque viam nela um indício de bom êxito na missão diplomática de que fora encarregado. $\mathrm{E}$ várias pessoas de Lisboa lhe mandaram também felicitações, entre as quais António Guedes Pereira que lhe escreveu com esse fim no mesmo dia do Cardeal da Mota $\left({ }^{11}\right)$.

Consequentemente, observou Sebastião José de Carvalho e Mello que esse casamento lhe trazia uma promoção na sociedade austríaca.

Os primeiros filhos, Henrique José Maria Adão Crisóstomo e Leonor Joana Maria Eva, tiveram como padrinhos respectivamente o Conde Henrique de Daun, marechal de campo $\left({ }^{12}\right)$, e o ministro português Marco António de Azevedo Coutinho, substituído na cerimónia pelo general Bento de Daun $\left({ }^{13}\right)$.

Descendente de uma família de pequena nobreza, comparecendo em Viena sem um título especialmente honroso e sem um motivo válido para ser considerado, esse casamento apresentava-lhe simultaneamente três factos a seu favor: um pretexto para doravante residir em Viena, uma oportunidade para conseguir o agrado da Imperatriz e um processo de conhecimento público da sua enviatura.

(') Ibidem, fl. 27, Carta de Manuel Pereira de Sampaio para Sebastião J. de Carvalho e Mello, Roma, 27 de Dezembro de 1745.

${ }^{\left({ }^{10}\right)}$ Ibidem, fl. 14, Carta do Cardeal da Mota para Sebastião J. de Carvalho e Mello, Lisboa, 27 de Janeiro de 1746.

(i1) B. N. L., Col. Pomb., cod. 717, fl. 105, Carta de António Guedes Pereira para Sebastião J. de Carvalho e Mello, Lisboa, 27 de Janeiro de 1746.

$\left.{ }^{12}\right)$ B. N. L., Col. Pomb., cod. 640, fl. 43, Certidão de Baptismo do primeiro filho de Sebastião J. de Carvalho e Mello, Viena, 13 de Agosto de 1749.

$\left.{ }^{(13}\right)$ B. N. L., col. Pomb., cod. 640, fl. 43, Certidão de Baptismo do primeiro filho de Sebastião J .de Carvalho e Mello, Viena, 13 de Agosto de 1749. 


\section{Em Viena de Austria}

\section{Referências d̀ vida quotidiana}

No fim da primeira metade do século XVIII, a mair parte das cortes da Europa possuiam um nível de comportamento que, desde as formas de indumentária, de mantimento, de habitação, aos divertimentos, às manifestações artísticas e às relações de convivência, podemos considerar luxuoso. Em Viena este nível da sociedade era ainda mais elevado, porquanto a Austria era um país extenso e rico. Havia, ainda, a favorecê-lo, uma tradição sustentada por famílias de antiga nobreza que tinham exigências nesse sentido.

Não eram completamente novas para Sebastião José de Carvalho e Mello as formas de vida que encontrava no Império. Também em Lisboa se vivia com uma certa magnificência. A este respeito, havia, sobretudo, grande fama na Europa. Numa das vezes que pedia recursos à corte portuguesa acrescentava "que isto procede muito mais fortemente a respeito de um Ministro de Portugal pelos empenhos em que o põem por uma parte o grande, e glorioso estrondo que nestas partes faz a alta reputação da magnificiência de S. Mag.d ${ }^{\bullet}$; pela outra parte a preocupação que há em Alemanha de que os Portugueses trazemos connosco o domínio, e o desprezo do ouro e diamantes do Brasil; e por outra parte as recentes memórias do Conde de Tarouca, o qual sem ter carácter, viveu nesta corte com cinco mil cruzados cada mês, e morreu empenhado pelo seu luzimenton ( $\left.{ }^{14}\right)$.

D. João V também tinha conhecimento destes factos. Por isso encarregava Sebastião José de Carvalho e Mello de saber em Viena se existia ou não uma lei mandada promulgar por Carlos VI segundo a qual era proibido o uso na corte de carruagens que tivessem menos de quatro rodas. Aliás interessava a D. João V quaisquer leis respeitantes ao luxo publicadas nas outras cortes. Pedia também ao enviado português a comunicação de outras normas semelhantes de que tivesse conhecimento de uso em Inglaterra ${ }^{16}$ ).

Pouco tempo depois o P. Carbone recebia em Lisboa uma carta de Viena com informaçōes concretas relativamente a esse assunto: "Tudo quanto V. Reverência conhece em Lis. boa por informacões de quem cabalmente conhecia o último Estado do luxo desta corte, tenho nella verificado por clara

(") Arquivo Nacional da Torre do Tombo, Negócios Estrangeiros, maço 157, Livro de Minutas de Viena, Carta de Sebastião J. de Carvalho e Mello para o P.e Carbone, Viena, 31 de Maio de 1746.

$\left.{ }^{15}\right)$ B. N. L., Col. Pomb., cod. 717, fls. 21 e 22, Carta de Marco A. de Azevedo Coutinho para Sebastião J. de Carvalho e Mello, Lisboa, 7 de Junho de 1745 . 
experiência. $\mathrm{O}$ número de criados é infinito; as librés são muito custosas, e muda-se, segundo as ocasiões em que se vestem: as carruagens tão bem luzidas à mesma proporção: as mesas frequentes estão carregadas de pratos redundantes, que cada jantar se podiam fazer dois para o mesmo número de pessoas em qualquer outro País: os alugueres das casas muito maiores que em Londres: os vestidos não só agaloados, mas ou todos cobertos, de gallas, ou bordados em cheio, e sempre acomodados à razão do tempo indispensavelmente além de os fazer repetidos a etiqueta da mesma corte, por se festejarem nela os dias dos anos, e dos nomes de todos os Príncipes da Casa de Austria, de sorte que nos dois Meses que há que aqui cheguei, entre lutos, pequenos lutos e galas, tenho sido obrigado cinco vezes a mudar de vestido. As cavalharices são numerosas à proporção de Castela: os ornatos da casa os mais preciosos: e as baixelas amplas porque os convites são sempre de vinte pessoas para cima entre a primeira nobreza. Finalmente nesta corte há casas que têm renda de seiscentos mil florins até cem mil. E sendo entre elas raríssima a que se não acha arruinada de dívidas, é necessário que a terra seja do grande luxo que deixo indicado" $\left({ }^{18}\right)$.

Fazendo a comparação com Portugal, Sebastião José de Carvalho e Mello dizia que, em Francfort, por exemplo, três apartamentos ou pequenas casas valem cem ducados, enquanto em Lisboa as do mesmo lote valem 15 a 20 mil reis por ano $\left({ }^{17}\right)$.

Não obstante, como se explica, sendo também Lisboa uma corte onde o luxo atingia formas de requinte e $\mathrm{D}$. João $\mathrm{V}$ um rei que tinha fama de rico na Europa, um enviado português numa corte estrangeira tivesse dificuldades de ordem financeira, a ponto de quase cair na «indecência» e no "desprezo das gentes»?

O P. Carbone e o Cardeal da Mota esforçavam-se por regularizar as finanças de Sebastião José de Carvalho e Mello em Viena, providenciando junto do governo de D. João V no sentido de serem satisfeitos os recursos que lhe eram necessários para não se ver em posição inferior à dos outros envia-

$\left({ }^{16}\right)$ Arquivo Nacional da Torre do Tombo, Negócios Estrangeiros, maço 157, Livro de Minutas de Viena, Carta de Sebastião. J. de Carvalho e Mello para o P.e Carbone, Viena, 30 de Agosto de 1745.

$\left(^{17}\right)$ Arquivo Nacional da Torre do Tombo, Legação de Portugal na Austria, Cx. A, Carta de Sebastião J. de Carvalho e Mello para Marco A. de Azevedo Coutinho, Viena, 11 de Setembro de 1745. 
dos aí residentes $\left({ }^{18}\right)$. Acrescia, porém, que Sebastião José de Carvalho e Mello tinha ainda algumas dívidas em Londres que era urgente satisfazer. Desses problemas tratavam em Inglaterra os seus procuradores Francisco Caetano, Daniel Flores e, já em 1749, Brás António de Basto.

Aos seus insistentes pedidos respondiam da Corte que «não havia El Rey tomado resolução positiva sobre esta matéria... que o tempo não tinha corrido favorável para as dependências deste género...» $\left({ }^{19}\right)$. De onde pode inferir-se que as dificuldades económicas suportadas por Sebastião José de Carvalho e Mello tinham a mesma origem que a falta de ordens da Corte de Lisboa e que a incerteza do carácter diplomático com que fora enviado.

Ainda no regresso a Lisboa, no fim da sua missão, com dificuldade conseguiu um subsídio para a viagem, por intermédio do P. Carbone, que lhe dizia em 8 de Junho de 1749: «Foi atendida esta minha reflexão, e se resolveu que dêm a Vossa Senhoria de ajuda de custo 15 mil cruzados, guardando-se porém nisto todo o segredo para que não sirva de exemplo» $\left({ }^{20}\right)$.

\section{Relações públicas}

Na sua vida pública em Viena, Sebastião José de Carvalho e Mello manteve um grande número de relações pessoais, constituídas em parte por membros da nobreza austríaca familiares de D. Leonor de Daun, diplomatas e enviados de estado, ministros ou funcionários ao serviço da Imperatriz Rainha, e alguns vultos do meio cultural austríaco.

$\left.{ }^{18}\right)$ Existem, na maior parte, na B. N. L., Col. Pomb., cod. 661. Não analisamos mais concretamente os problemas financeiros de Sebastião J. de Carvalho e Mello em Viena porque são, por si mesmos, bastante complexos e só num estudo orientado exclusivamente nesse sentido podíamos chegar a conclusões seguras. Os códigos 100 e 719 da mesma colecção contêm muitos elementos a esse respeito. $O$ códice 719 é um original incompleto que consta, de fl. 1 a 45 do «Rol das despesas de viagem desde Viena a Madrid e a Portugal, em língua francesa». O códice 100 é um livro das «entradas dos mossos e creados que servem em esta Corte de Viena de Áustria ao Sr. Sebastião Joseph de Carvalho e Mello, Inviado de S. Mag.d` à corte de Londres... com as despesas de librés e ordenados». J. Lúcio d'Azevedo, ob. cit., da pág. 76 tirou algumas conclusões referentes a esse aspecto. Este assunto será objecto de um trabalho especial, em preparação.

(iv) Arquivo Nacional da Torre do Tombo, Negócios Estrange1ros, maço 157, Livro de Minutas de Viena, Carta de Sebastião J. de Carvalho e Mello para o P. Carbone, Viena, 23 de Setembro de 1747.

$\left(^{20}\right)$ B. N. L., Col. Pomb., cod. 661, fls. 110 a 111. 
Verificando os nomes das pessoas que o visitaram desde 1 de Janeiro de 1746 a 10 de Março de 1748 , período central da sua estadia em Viena, concluiu-se que só uma minoria de pessoas representativas no Corte o não honraram com a sua visita pelo menos, para um cumprimento protocolar. A insistência de certos visitantes leva-nos, além disso, a deduzir que Sebastião José de Carvalho e Mello era pessoa considerada pelas atenções públicas $\left({ }^{21}\right)$. Facto que não é de estranhar tendo em conta que a Imperatriz Rainha lhe dispensou também, excepto em momentos pouco favoráveis à mediação portuguesa, uma especial atenção, em relação com os enviados estrangeiros residentes naquela Corte.

Na sua correspondência, porém, Sebastião José de Carvar lho e Mello não refere a maior parte dos nomes que podemos ver na lista das suas visitas, ou porque nas cartas oficiais não convinha citá-los, ou porque o seu conhecimento não interessava às pessoas com quem mais particularmente se escrevia.

As únicas personagens a que encontramos alusão nas suas cartas e cujos nomes também figuram nas suas visitas são os médicos que o tratavam, dada a contínua falta de saúde de que sofreu durante esta missão diplomática. Foram eles o holandês Von Switen; o português Manuel Sanches; Kesler, de que não se indica a nacionalidade; e um "doutor em medicina da corte de Moscóvia». O holandês Van Switen foi também o médico particular da família imperial. Dizia Sebastião José de Carvalho e Mello numa das cartas a Marco António de Azevedo Coutinho, de 26 de Abril de 1747, que ele tratava naquela altura a Imperatriz Mãe. «O dito Proto.Médico servindo-se de uma moderníssima observação da Sociedade Real de Londres principiou logo a aplicar repetidas exibições de Kina Kina pela boca, sem aplicar outro remédio tópico. Pelo meio das ditas exibições de Kina Kina se purificou o sangue. Por consequência, cessou a grangrena...» $\left({ }^{22}\right)$.

Desta informação se conclui que em Viena se acompanhavam os progressos da medicina no estrangeiro e se punha à prova o seu valor prático. Não faltavam ocasiões a Sebastião José de Carvalho e Mello de os poder utilizar. Na verdade, salvo muito raras excepções, as cartas remetidas de Viena começam por uma pormenorizada descrição das suas doenças. Escrevia, por exemplo, ao P. Manuel de Azevedo, em 9 de

$\left({ }^{21}\right)$ Os nomes das pessoas que o visitaram neste período de tempo encontram-se na B. N. L., Col. Pomb., cod. 718.

$\left({ }^{22}\right)$ Arquivo Nacional da Torre do Tombo, Legação de Portugal na Austria. Cx. A. Carta de Sebastião J. de Carvalho e Mello para Marco A. de Azevedo Coutinho, Viena, 26 de Abril de 1747. 


\section{Em Viena de Austria}

Maio de 1748, que estivera seis semanas doente a ponto de ficar cego, vivendo instalado, por esse motivo, durante algum tempo numa câmara escura $\left({ }^{23}\right)$.

Porém, embora não se refira directamente, na sua correspondência, às pessoas com quem mais assiduamente convivia, sabe-se que, entre elas, figuravam, com certeza, os fidalgos das Casas de Daun e Peyersperg. Verificamos, com muita frequência, serem suas visitas os Condes Max, Leopoldo, Filipe, Carlos e Bernardo, de Daun; e para D. Leonor, a Condessa de Peyersperg e damas de honor da mesma Casa.

Além destas pessoas de família, Sebastião José de Carvalho e Mello recebia em sua casa numerosas figuras principais da nobreza austríaca. Algumas encontram-se quase diariamente com o ministro português. Entre estas contavam-se: o barão de Agilar, o Conde de Althann, o General Ariosti, o Conde Aursperg, o Barão de Bechmann, o Conde de Bergen, o Conde de Breuner, o General de Cunia, o Príncipe de Dietrichstein, o Pr ncipe José de Esberhasi, o General de Franchenberg, o Conde de Gabriani, o Conde de Grusbach, o Reverendo Gundl, o Conde de Hardigh, o Conde de Koschenski, o Conde de Kevenhiller, o Conde de Kenckel, o General Lusani, o Marquês de Nicolini, o Marquês de Perles, o Conde de Riscourt, o Conde de Salm, o Conde de Schaffgotoh, o Conde de Staremberg e o Marquês de Versoni.

Com menor frequência visitavam a sua família: o Conde de Algorotti, a Duquesa de Bechle, o Conde de Branchis, o Barão de Bechmann, o Conde de Cervillion, o Conde Zigonio Colonel, a Condessa de Douriere, a Marquesa de Duchatex, o Barão de Egkh, o Conde de Endler, a Condessa de Engl, o cavaleiro Frigelfil, a Condessa de Frinfkirechen, o Conde de Lalaing, a Condessa de Komysegg, a Baronesa de Kircner, a Condessa de Julien, a Duquesa de Hollenstein, a Princesa de Hodize, a Condessa de Heiblin, a Princesa de Lamberg, o Príncipe Manuel de Lichtenstein, a Condessa de Luserano, a Condessa de Mallard, o cavaleiro espanhol D. Horêncio Salana e Maldonado, o Conde de Milesimo, a Condessa Josefa de Nostitz, o Marquês de Paucio, o Conde de Pantolfi, o Conde de Pergen, a Condessa de Prekler, o Conde de Poquoy, o Marquês de Puil, o Marquês de Richi, o Marquês de Russerano, o Barão de Sallersheim, a Condessa de Schonborn, a Condessa de Seillern,

("3) Iojidcm, Carta de Sebastião J. de Carvalho e Mello para Marco A. de Azevedo Coutinho, Viena, 9 de Maio de 1748. 
o Marechal Serin, o General Taffe, a Condessa de Trantmostorf, a Condessa de Virmund, o Marquês de Visconti, o Barão de Zoblin, o Conde de Wilscheg, o Conde de Windisgratz, e o Marechal de Wutenbrande. E os portugueses: Conde Francisco de Vasconcelos, Conde de Monte Santo, D. Manuel, oficial do Infante D. Manuel de Portugal, "monsieur» da Motta e Manuel Teles da Silva.

Além destas relações, e na qualidade de ministro português em Viena, Sebastião José de Carvalho e Mello mantinha uma necessária convivência com os outros ministros de estado aí residentes entre os quais se contavam nomeadamente: o ministro da Baviera, o Chanceler da Boémia, Príncipe d'Harrach, o enviado do Hanover, o Barão Fritsch "conselheiro íntimo de Sua Majestade o rei da Polónia», o enviado de Inglaterra Monsieur Robinson, o enviado da Holanda, o auditor de Roma Megazi, o enviado da Moscóvia, o Chanceler da Hungria Neodasti, o Núncio de Roma, o Núncio da Polónia, o enviado da Prússia, o enviado do Saxe conde de Loss, Stosini, secretário do arcebispo de Viena Cardeal Kollonitz e o embaixador de Veneza.

Houve, porém, um outro tipo de relações mantido por Sebastião José de Carvalho e Mello no meio político e social austríaco que adquiriu maior importância e significado: a comunicação com ministros do próprio governo de Viena, especialmente com os Condes Welfeld, Kaunitz, Harrach, Sinzendorf e Kinsky.

Não sabemos, concretamente, se destas anteriores relações resultaram influências definitivas no espírito do enviado português, porque na sua correspondência não encontramos nenhuma alusão nesse sentido. Além disso, as reformas levadas a efeito por estes ministros, incluídas nos planos de centralização política da Imperatriz Maria Teresa, só tiveram realização sistemática depois da paz de Aix-la-Chapelle, quando os domínios da Casa de Austria ficaram efectivamente em paz.

A missão diplomática de Sebastião de Carvalho e Mello termina ainda em 1748, sendo o seu regresso adiado para 1749. Não podia por consequência, ser influenciado pelo conhecimento directo dessas reformas, visto que o sistema administrativo de Kaunitz só teve realização a partir de 1761, as reformas financeiras de Harach e de Kinsky surgiram depois das medidas tomadas por Haugwitz em 1749, e a de Sinzendorf só teve lugar a partir de 1762. Deste modo concluímos que das relações de Sebastião José de Carvalho e Mello com ministros reformadores do governo austríaco não advieram resultados 
práticos que viessem a ser utilizados no período da sua administração no reinado de D. José $\left({ }^{24}\right)$.

Não teria havido, porém, nenhum aspecto positivo nas influências ideológicas (de economia, cultura ou política) assimiladas durante esta enviatura e depois transmitidas para Lisboa?

(24) Diz J. L. d'Azevedo, (ob. cit., pág. 89), referindo-se à pouca aptidão de Sebastião J. de Carvalho e Mello para assimilar influências no estrangeiro: «Por isso do estrangeiro só trouxe um progresso, se tal é lícito dizer, tardio. Seus voos altos para o nível da razão do país, foram, se em absoluto os considerarmos, mesquinhos. Nenhum dos grandes ideais, que agitavam os cérebros pensantes da Europa, teve guarida no seu. Modelos foi-os buscar mais de cem anos atrás. Em assuntos económicos quis por mestre Sully; em política tomou por guia Richelieu. Acaso de aplicação de processos antiquados resultou o malogro da sua obra». 